\title{
Entre a fala e a escrita
}

\section{José Mariano Neto*}

\begin{abstract}
Resumo: $O$ trabalho pretende confrontar as personagens Domenico Scandella, do livro $O$ queijo $e$ os vermes (GINZBURG, 1987) e Paulo Honório, do romance São Bernardo (RAMOS, 2006) como pertencentes ao mundo da oralidade, e de dividirem uma heroicidade derivada do uso da palavra, em contrapartida ao fato de serem homens muito simples e pertencem a estratos socioculturais populares.
\end{abstract}

Palavras-chave: história; memória; romance; interações; convergências.

\begin{abstract}
This work intends to confront the characters Domenico Scandella, from the book $O$ queijo e os vermes (GINZBURG, 1987) and Paulo Honório, from the novel São Bernardo (RAMOS, 2006) as belonging to the world of orality, and sharing a heroism derived from the use of speech in opposition to the fact of both being very humble men and belonging to the lower classes.
\end{abstract}

Keywords: history; memory; novel; interactions; convergences.

\section{Introdução}

Em um primeiro momento, tomaremos como fio condutor deste ensaio o fato de que Menocchio, personagem central do livro O queijo e os vermes, de Carlo Ginzburg, foi alguém que pautou sua vida pela palavra. Vivendo numa comunidade orientada pelas práticas, na sua maioria, movidas pela oralidade, nosso 'herói' era um camponês que lia e, por sua vez, distinguia-se dos demais na pequena aldeia em que morava. Se o caso fosse apenas de interesse pessoal de leitura sobre o mundo, que atendesse imediatamente às necessidades daqueles que viviam do campo, ou como curiosidade que não ameaçasse a ordem vigente, Menocchio passaria despercebido da 'polícia' medieval e não infringiria as normas da sociedade à qual pertencia. Porém, seu 'grande pecado' era produzir uma experiência de pensamento que implicava a expressão pública de pontos de vista que eram desviantes (em relação à norma), além de saber 'ler' o que estava a seu redor.

O que Menocchio desferia com palavras, publicamente, como fruto de suas leituras, embora fosse do âmbito da subjetividade e da imaginação criativa, ameaçava frontalmente o status quo, o que o condenava à solidão (oficializada pela repressão social e religiosa) e à falta de ouvintes (seus contemporâneos eram muito medrosos), pois se contrapunha, com suas 'idéias fora de lugar', à ideologia reinante e desafiava o medo imposto àqueles que pensavam com liberdade. Menochio, nosso moleiro, era exemplo do estreitamento entre escrita e

\footnotetext{
* José Mariano Neto (Doutorando) - Universidade Federal da Paraíba (UFPB), PPG-LET.
} 
intelecção, na medida em que não absorvia passivamente o conhecimento dado e instituído (ou, ao menos, o que era permitido circular nos textos impressos de sua época). Ele recriava os universos constituintes de um determinado saber erudito, de modo a poder aplicá-lo ao próprio cotidiano, de forma a alterar a sua prática de dia-a-dia. O resultado dessas leituras era filtrado pela concepção 'comezinha' de mundo do moleiro, passando pelo crivo de uma sociedade marcadamente rural e supersticiosa, privada de acesso a um mundo que era letrado e abastado, no qual não havia possibilidade de participação política e ascensão social.

Devemos atentar para o fato de que a cultura clerical e erudita tinha verdadeira abjeção à cultura folclórica que Menocchio inevitavelmente representava com seus discursos 'heréticos'. A camada culta dos reis e dos representantes religiosos aparelhava-se de um sistema de circulação de saberes que procurava, a qualquer custo, impedir todo pensamento ambíguo e equívoco oriundo da camada popular que colocasse em xeque a cultura hegemônica. Porém, mesmo em meio à repressão do pensamento original daqueles que viviam no e do campo, não impedia que as massas reivindicassem um cristianismo mais próximo de sua realidade, uma vez que a mensagem veiculada pelo clero se tornava uma via de mão única, tão cifrada em si mesma, que se restringia à compreensão somente dos seus próprios enunciadores, hábeis na manipulação dos signos que requeriam uma espécie de iniciação na arte de ler 'mistérios'.

Os anseios populares, que em certa medida eram presentificados por Menocchio nas suas falas, revelavam a desigualdade entre dois mundos: o clerical e o popular ou folclórico. Daí, também, justificar-se muitas das interpretações livres dos textos sagrados que fazia o moleiro e o fosso fomentado entre a exegese cristã ortodoxa e a sua, particular, calcada na formação sociocultural rural, supersticiosa e alegórica.

Não descuidamos, no entanto, de que Menocchio, em certa medida, apresenta (e representa) um cristianismo 'revolucionário', dos pobres, ao se rebelar contra a ordem clerical injusta e elitista, embora ele mesmo se veja desajustado não somente, e ao mesmo tempo, à classe camponesa à qual pleiteia uma leitura e uma prática do religioso mais condizente com ela, mantendo-se à frente da sua época e dos seus pares.

Menocchio opera, com e pelo discurso, algo paradoxal: sendo camponês, e condicionado a essa realidade socioeconômica, ele pensa e não sente como alguém próprio do campo. O que ele pensa sofre influência do sistema folclórico no qual está contextualizada sua profissão e a expectativa de seu desempenho intelectual. Às suas leituras dos textos cultos são adicionadas impressões do mundo dinâmico das mistificações e da mentalidade campesina. Por outro lado, o moleiro se sente como alguém inapropriado ao meio em que vive. É uma 
voz que destoa do senso comum, de modo que persegue o entendimento da desigualdade entre os homens, no que importa serem eles clérigos (a hegemonia socioeconômica e cultural da Idade Média) e reis, ou meros trabalhadores de feudos e semi-escravos do primitivo modo de produção da época (há uma desrrazão na pertença ao 'populacho': o não-gozo de igual dignidade de que usufruem os dignitários da fé e do poder).

Menocchio estava dividido entre dois mundos: o da cultura popular, da tradição oral (embora ele possuísse determinado letramento), e o da cultura erudita, letrada e da escrita. Ele se apropriava de um conhecimento circulado pela imprensa e pelo livro, no entanto, suas inferências desse mundo da escrita estão atreladas à realidade do campo. A circularidade dos dois níveis de cultura possibilita perceber claramente a predominância de uma sobre a outra. À cosmogonia herética e 'delirante' de Menocchio confluem temas populares e eruditos apreendidos da própria experiência de mundo e de leitura de diversos livros em que se mesclam muitos universos. Se pode afirmar que uma dicotomia permeia sua leitura de mundo, a qual faz ver a cisão entre sociedade culta e folclórica (ou do campo), ao mesmo tempo em que se vislumbram interseções entre elas.

Sabe-se que a condição de subalternidade do moleiro justificava a repressão às suas atitudes heréticas, uma vez que saltava aos olhos o desprezo com que o Santo Ofício e seus representantes tratavam as populações pobres e incultas e suas tradições, somando-se a isso o repúdio à cultura popular e às expressões de cunho folclórico a que as interpretações exegéticas de Menocchio estão arraigadas. Dessa forma, não espanta que havia algo de muito acintoso na leitura dos textos sagrados feita por Menocchio. Entretanto, o sua maior heresia consistia em 'combater' os privilégios da classe eclesiástica e dos poderosos, lançando o questionamento sobre a igualdade entre os homens que o próprio Cristianismo legitimava através dos textos bíblicos. A reflexão que ele faz sobre a institucionalização de direitos exclusivos da classe clerical e dos reis aludia à distância entre os donos do poder e da religião e o povo.

O cristianismo de Menocchio remonta, historicamente, às origens de uma fé cujas raízes estavam localizadas na existência simples e prática dos homens do campo, onde cotidiano e ações respondem aos desafios pontuais de uma realidade inalienável que dava pouca margem para o 'escapismo', próprio do moleiro, do qual serve como concepção livre do mundo e atributo de danação, já que pensar o mundo da forma como ele fazia tinha implicações políticas desafiadoras que mexiam com os brios da fé e dos poderosos.

O tom reflexivo em que se situa o discurso de Menocchio é o ponto-chave de um poder em mãos erradas: alguém de classe inferior, alvo constante do controle e da repressão, 
que se arrogava uma capacidade (inadmissível) de questionar a classe culta e letrada, seus dogmas, seus desmandos, sua arrogância, seus privilégios e sua própria legitimação como poder absoluto, não poderia deixar de chamar a atenção por muito tempo, em vista do incômodo e da ameaça de um discurso dissonante que não tinha meias-palavras para desmascarar a hipocrisia e o os abusos de força da Igreja.

Parece-nos que o que estava em jogo na condenação de Menocchio à fogueira não é tão-somente suas heresias contra os dogmas religiosos cristãos, mas sua palavra incendiária, ameaça concreta à formação de um contingente de dissidência e revolta que podia fazer desestruturar o tecido social e os estamentos rígidos e cristalizados pelo tempo, capaz de suscitar outros modos de organização da fé e da sociedade da época. Não se podia admitir um grande levante popular que tivesse força suficiente para desafiar o mundo da erudição e da fé, sendo necessário, então, calar a possibilidade de ocupação espacial dessa voz no meio social.

As sementes de descrença do moleiro são as palavras de uma autonomia da criação da própria voz, subjugada pela mordaça que oficializava o silêncio. Essa voz constituía uma interpretação original da existência e reclamava liberdade na concepção do mundo no que ele possuía de mais anticonvencional, ao mesmo tempo em que se 'desassujeitava' e abria fendas para as representações individuais, acenando para uma cultura do não-pertencimento imposto, que exigia o reconhecimento negado pela História. Para isso, a palavra de Menocchio teve de incorporar em carne viva a dissidência e pagar o preço de si mesma, pela ousadia de ser livre, recusando o silêncio que atravessava as palavras. Menochio vislumbrava um mundo em que o mais importante não devia deixar de ser dito, pois não dizê-lo compreendia reforçar o mutismo de um mundo no qual se fundava em calar as vozes cujos discursos da alteridade e da individuação eram condenados a viver sem significação.

\section{0 dilema repetido}

A discussão sobre a representação de um novo modo de produção em um Brasil ainda muito atrasado, instaurado por Paulo Honório em São Bernardo (RAMOS, 2006), não nos parece de menor importância que, por exemplo, a pertença do protagonista ao mundo da oralidade. Embora, estruturalmente, no romance, essa dicotomia assuma o estatuto de algo irresoluto (como pode a novidade do capitalismo se associar ao iletramento do herói?), provocando muitos questionamentos em torno do problema, acreditamos na existência de uma relação de dependência entre forças tão distintas, que, vistas superficialmente, anulariam uma à outra. A relação explícita entre modo de produção e iletramento não se resolve no texto, mas 
nas entrelinhas. A necessidade da escrita para Paulo Honório tem seus conluios com o modo capitalista de produção na medida que escrever o faz pertencer ao mundo daqueles que, de algum modo, precisam ter o controle sobre as coisas e os homens - como poder sobre a realidade. A escrita romanesca (não estamos falando ainda do estatuto da ficcionalidade), a tentativa bem lograda de 'romancear' a própria existência não deriva do caráter sensível do narrador, mas da aquisição do contador de histórias de toda uma tradição da oralidade.

O sucesso da novidade do capital sobre o meio rústico, a potencialidade de transformação das velhas formas de vida por um outro jeito de condução, não desfaz a carapaça nem a interioridade (o pensamento e os costumes) do homem povoado de superstições, crendices, que é Paulo Honório. Sua humanidade (talvez fosse melhor tratar de sua desumanidade) não reside exclusivamente na maneira capitalista de direção do seu empreendimento, mantendo uma proximidade com o que há de mais atrasado, bruto e cruel na história das relações produtivas, chegando a lembrar o escravismo anacrônico e sua perversidade, não muito fora de lugar, mas contraditoriamente, excrescente à época.

Ao tentar buscar elucidação para o modo como resolveu conduzir sua existência, ao provocar o reconhecimento do próprio fiasco como personagem humana nas inter-relações com os homens, as memórias do narrador oferecem interesse a outras áreas de conhecimento, fazendo pensar a escrita como literatura, como modo de contar, e o conto como experiência como relato do passado que pode servir de esclarecimento pessoal e de exemplo à posteridade. Levando-nos a refletir sobre a psicologia do homem, sobre seus envolvimentos sociais, e a própria memória singular como história individual, o narrador provoca como que uma espécie de aprofundamento reflexivo sobre a capacidade humana de reter o passado e de como o resultado dessa rememoração pode ser vertido para a forma literária memorialística.

Quando Paulo Honório se vê às voltas com a necessidade inelutável de produzir em texto o que foi fruto da difícil experiência existencial, entram em jogo dois campos de elaboração estética distintos, o da memória e da oralidade e o da escrita e o do conto. Para ele, esses dois mundos vivem em desacordo contínuo, uma vez que à esfera das coisas que podem ser compreendidas pela fala dizem respeito direto ao mundo prosaico em que ele mesmo está envolvido em sua faina medonha de produzir e acumular bens e seres; ao mundo diferenciado da escrita pertence a arte da ficção, já que sobre a assertiva do narrador de que "é preciso trazer para o texto o jeito como se fala no cotidiano" está imbricada a noção de não subverter a ordem da realidade de que a literatura ficcional comumente é capaz.

As pressões exteriores por que passa o narrador, como por exemplo, a da existência, via a fala de Azevedo Gondim, de um estatuto que rege o mundo da escrita, subentendendo 
que brigar contra os imperativos sociais da língua instituída não lograria sucesso à empreitada própria da escrita de um livro ["A gente discute, briga, trata de negócios naturalmente, mas arranjar palavras com tinta é outra coisa.” (RAMOS, 2006, p.9)], faz ver um narrador que escolhe a escrita personalizada, não por desconhecimento do abismo que está cavando ao escrever como se fala, mas como tentativa de não trair a si mesmo em suas origens de homem inculto.

Pelas razões sociais expostas pela narrativa, sabemos que Paulo Honório é um 'bruto'. Seu 'abc' tem como medida a Bíblia lida nos tempos de encarceramento, longe de toda sugestão moral, pois o protagonista é um homem prático e não dado aos 'salamaleques' típicos de quem se sujeita à educação formal. Seus parcos conhecimentos se restringem à urgência do mundo do trabalho rural. Para ele, soa estranho o refinamento intelectual, embora aqui e ali, no texto, percebamos uma admiração pelo mundo da cultura, ao qual ele não vislumbra nenhum pertencimento.

O motivo pelo qual é impelido a construir uma escola no terreno da fazenda de São Bernardo não se trata de altruísmo de educador adormecido, mas da estratégia política de exercer influência e de angariar benesses junto aos poderosos. Paulo Honório não reconhece a possibilidade de esclarecimento que a educação pode facilitar: para ele interessa "saber ler os manuais de vida prática e os almanaques sobre a vida rural, e somar e multiplicar”. A empresa do protagonista tem fins bastante imediatos, que é o de verter para o papel sua própria história sem os artifícios peculiares do escritor, configurando o desejo de resgatar algo submerso que explique o presente, mas sem um fim 'iluminista', convertendo-se tão-somente em um instrumento de autopreservação, eliminando a alternativa da busca de um sentido para a vida na suas relações com os homens.

A construção da memória por meio da linguagem do outro inviabiliza o projeto pessoal do narrador: a necessidade de narrar com o próprio punho a história pessoal tem lá as suas relações de evitar que algo nela seja adulterado, como é da alçada do literário e se tornou uma convenção assim. Talvez possamos inferir que por trás de Paulo Honório está em pleno funcionamento o projeto estético do autor, para quem "a palavra não foi feita para enfeitar, brilhar como ouro falso" (RAMOS, 2006, contracapa). O que nos parece, sim, é que a opção de contar a história sob a ótica personalística, coloca em andamento uma forma de nãoassujeitamento característico de quem detém os meios de produção.

O poder em Paulo Honório está exclusivamente localizado na sua capacidade de possuir os instrumentos de manutenção do regime que ordena a vida no campo. Seu reduzido vocabulário de sertanejo o incapacita a mobiliar uma narrativa com descrições detalhistas ou 
manifestações excessivas de sentimentalismo, expressões de uma escrita que dêem notícia do domínio da língua e da linguagem, de determinados maneirismos e de estilo, enfim, que mostrem um escritor em pleno domínio do seu ofício.

O narrador em São Bernardo tem total consciência de não pertencer ao 'clube' dos letrados, dos 'domadores' da escrita. Paulo Honório só consegue predominar sobre os outros porque ele mostrou que pouco importa a cultura e o saber eruditos quando o capital é maior, quando o dinheiro fala mais alto do que todos os valores humanos. No entanto, não escapa ao protagonista argúcia e inteligência, como seriam próprias de admitir, vindas de alguém que tivesse tido seus muitos anos de escola. O que importa é ter os instrumentos de trabalho para fazer a terra produzir riquezas e estar de posse da mão-de-obra, 'sabendo' que para isto não é exigido refinamento intelectual e moral.

De proprietário de terras a 'contador da própria história' a distância é bastante grande: uma coisa é o domínio dos bens de produção e dos homens e outra, bem diferente, é manter-se nos limites da exatidão e da clareza a que a escrita de uma narrativa, forçosamente, o arremessa. Daí, concluímos que, no texto, convivem, não pacificamente, dois movimentos contrários, e até mesmo antidialéticos, um procurando destruir a força do outro: a ordem das coisas e a natureza humana.

O projeto de construir o livro pela divisão trabalho, imediatamente, evoca a vida vivida pelo protagonista, a qual está permeada da reificação dos homens. No final de São Bernardo, Paulo Honório cede à subjetividade, deixando ver os "signos da deformação e da monstruosidade" (LAFETÁ, 2004, p.101) que a auto-reflexão faz circular no monólogo interior, mostrando a prepotência de forças na administração da vida, cujo resultado culminou na anulação dos homens pelas suas mãos.

O que estamos tentando mostrar ao longo dessas especulações, conforme acenamos no início deste trabalho, é que no romance de Graciliano Ramos duas forças opostas contribuem na constituição do protagonista: a de homem empreendedor que busca incorporar à fazenda São Bernardo as novidades do capitalismo (evidentemente, às custas de muita sagacidade e 'esperteza'), e a do sujeito iletrado, cuja personalidade (costumes, moral, e mundivisão) está vincada pela oralidade, pela superstição, pelo crivo e ordem de uma sociedade patriarcal, atrasada e preconceituosa, personalidade que define os seus inter-relacionamentos.

\section{Menocchio e Paulo Honório no mesmo banco de réus}


Não nos estenderemos na questão da reificação presente no romance, muito explorado pela crítica, porque nossa intenção é outra: queremos mostrar como Paulo Honório, pertencendo ao mundo da oralidade, comunga, em certo sentido, das mesmas características que formam a personalidade do moleiro perseguido pela Inquisição, Domenico Scandella. Mantidas as devidas diferenças contextuais, tanto Menocchio quanto Paulo Honório dividem uma heroicidade derivada da palavra.

Expliquemo-nos: os dois sujeitos das duas histórias têm em comum um certo hábito de leitura - em contrapartida são homens muito simples. É verdade que em O queijo e os vermes (GINZBURG, 1987) não vislumbramos a mesma ascensão socioeconômica que a do protagonista Paulo Honório, romance de Graciliano: o herói medieval não possui a astúcia de 'passar a perna nos outros', não no sentido tão brasileiro de levar vantagem, como é típico no herói nordestino. Mas, igualmente, os dois usam e abusam do status de pertencerem a uma classe de pessoas que os distanciam, imediatamente, do meio de onde provêm.

Essa condição social a que nos referimos diz respeito ao letramento por que passam: é impossível desmentir o vínculo existente entre a capacidade do uso de diferentes tipos de material escrito e uma diferenciação, ainda que muito subjetiva em certo sentido, de quem possui apenas a destreza e domínio do mundo da oralidade. Saber ler e escrever é distintivo em uma sociedade ainda agrária e folclórica, aumentando a distância que costuma haver entre conhecimento empírico e saber erudito.

O conhecimento do protagonista de São Bernardo se restringe ao dia-a-dia da vida rural, o que faz pensar que a subjetividade não pode ocupar espaço nas lidas das coisas do campo. Não é a toa que Paulo Honório procura escrever um livro sob o punho de outros personagens, mais cultos, pertencentes ao mundo da escrita, porém, o excessivo esmero destes com a palavra estabelece um recuo no projeto, pois para o proprietário da fazenda o que importa é um relato que transpareça os acontecimentos tais como eles se deram, com a mesma exatidão com que ele trata da terra e dos homens que trabalham nela. A subjetividade só é acolhida na intimidade, pois ela pareceria se contrapor à ordem urgente de tratamento do cotidiano no campo. De tal forma, parece-nos, assim se dá com Menocchio: para o moleiro, as elucubrações derivadas de suas leituras de textos sagrados ocupam o espaço das conversas que ele mantém com outros vizinhos e na sua própria 'exibição' ao tribunal do Santo Ofício. Menochhio não é alijado do convívio humano pelas vozes interiores que o povoam, mas pela palavra compartilhada com os seus pares.

Evidentemente, há a diferença intrínseca e externa entre as duas personalidades, que é a de a palavra de Menocchio se circunscrever à fala como expressão de seus pensamentos e 
modos de ver o mundo, e a palavra escrita de Paulo Honório em forma de texto discursivo. A evolução entre uma modalidade e outra sugere uma distância dos usos instituídos e da importância que eles tinham em cada sociedade. Soa estranho um moleiro naquela época possuir a intelecção que Menocchio tinha, da mesma forma que não nos parece muito verossimilhante o texto escrito por Paulo Honório, um sujeito, como ele mesmo se autoproclama, bruto, rude, insensível. A palavra para os dois protagonistas, ainda que de textos muitos dessemelhantes, significa uma forma de possessão poderosa com a qual eles se distinguem dos seus contemporâneos e, infelizmente, os condena também ao isolamento e à falência como seres humanos, considerando, claro, os motivos que vilipendiam e alijam-nos.

Não ocorre na história de Ginzburg de o moleiro se dar ao luxo de questionar a própria existência sob o crivo da mesma subjetividade de Paulo Honório: o que acontece no texto de Graciliano é a representação moderna de alguém envolvido em seu ensimesmamento, falando somente para si mesmo, muito característico de um acerto de contas com a própria consciência. Aqui, vemos o texto conformar-se a outro tipo de ordem representacional, que ainda não era posto em circulação na Idade Média. Ginzburg escreveu O queijo e os vermes na década de 1970.

Esteticamente, o romance reflete uma época distante na qual a subjetividade era motivo de perscrutação pelas autoridades eclesiásticas, temida pela sociedade laica, muito diferentemente da elaboração utilizada para dar conta da interioridade dos personagens romanescos a partir da modernidade, como por exemplo, os efeitos representados pelo fluxo de consciência, provocados pela simultaneidade dos pensamentos.

Como a distância entre os contextos representados pelos romances é enorme, podemos imaginar entre um e outro uma certa evolução temporal da técnica e uso da subjetividade como fundamento estrutural da forma estética. Porém, o que está em questão aqui neste trabalho não é mensurar os transcursos que as técnicas romanescas (embora o Queijo e os vermes não seja precisamente um romance) sofreram ao longo do tempo, mas tentar aproximar os protagonistas de $O$ queijo e os vermes e de São Bernardo no que eles têm de comum no uso da coloquialidade como forma discursiva e, sabendo que nos romances se privilegia a palavra como elemento desencadeador da trama e dos conflitos, descobrir como o discurso originado pelo mundo bruto e iletrado define a personalidade dos principais personagens, suas relações e seus modos de ver o mundo.

O dilema entre a voz e a escrita para Menocchio é da mesma dimensão do paradoxo de escrever como se fala, vivido por Paulo Honório. Não vislumbramos a separação entre fala e escrita no romance de Graciliano Ramos, como fica estabelecida no livro de Ginzburg, uma 
vez que a dificuldade de acesso à cultura pela classe rural, na Idade Média, circunscrevia o letramento e a intelecção às elites econômicas e religiosas. Mas, o trânsito fácil ao mundo das letras para Paulo Honório não o torna menos limitado, menos bruto e menos incapaz mesmo de pertencimento ao grupo de homens cultos.

A escrita para ele não é uma habilidade adquirida que representa o aprendizado de leitura de mundo, sofisticação espiritual, ou uma maneira de requinte moral... Não! Paulo Honório não é dado a essas 'sutilezas', ele é um homem prático, um capitalista, alguém que procura obter resultados imediatos de suas ações. A sensação de apartação social experimentada pelo protagonista faz com que ele lembre o tempo todo o lugar de onde veio, suas origens, sua pobreza, seus modos rudes, em meio à segurança da posse da propriedade e das pessoas que compõem o quadro humano de São Bernardo.

O espanto com o qual nos deparamos com um narrador em pleno domínio do registro culto da língua, destreza que falta a Paulo Honório, evidentemente, pelo seu relato de que é incapaz de "acanalhar" a história pessoal [“" - Vá para o inferno, Gondim. Você acanalhou o troço. Está pernóstico, safado, está idiota. Há lá ninguém que fale dessa forma” (RAMOS, 2006, p.9)], resulta da consciência que toma o leitor ao longo da narrativa de que soa "sem verdade" à própria narratividade o discurso em primeira pessoa de um sujeito tão deslocado do mundo da palavra.

Se levarmos em consideração que, ao modo de um narrador que mantém controle total sobre o que é contado, suprimindo assim muitos dos detalhes e descrições dos fatos, como é da competência do narrador de que trata Walter Benjamin (2002, p.153-154), ainda que se faça prevalecer no texto apenas o que é possível lembrar do passado, o que evita que o narrador entre em contato com o esquecimento e o silêncio, para o bom andamento da narrativa não nos parece convincente que a Paulo Honório se poderia designar tal acuidade, nem a do controle da situação memorialística, nem tampouco a do domínio da expressividade da narração dos eventos passados. O mesmo processo se dá com Menocchio ao fragmentar, e não somente isso, mas evaporar, o sentido que permeia todos os textos que ele mesmo leu: é verdade que temos um processo contrário aqui, em que entra em cena o poder criador da imaginação delirante do moleiro, associado ao pensamento supersticioso e folclórico oriundo do seu meio social e do qual é a matriz de suas 'especulações' muito personalistas.

Mesmo que aleguemos que não escapa a Paulo Honório uma filiação ao mundo mítico e místico nordestino que é retratado em São Bernardo, não reside nesse narrador a visão de um homem simples do povo, mas a de alguém que possui uma especial faculdade de 
letramento e de intelecção, e acima de tudo, a de assegurar ao texto a representação do real, habilidade, que ele não pode assumir.

A ignorância intelectual de Paulo Honório não permitiria a representação, por suas mãos, de um narrador que ultrapassasse a falta de cultura literária que ele mesmo admite textualmente e da qual se envergonha, de tal sorte que o romance cria como que um impasse em sua própria estrutura e enredo, trazendo à tona um herói, uma aventura e uma luta, elementos essenciais à forma, que provocam o deslocamento entre o que é narrado e a personagem portadora da narração, fazendo ver níveis de concisão e de expressividade e de desvendamento metalingüístico que aferem uma maturidade literária, impossível de ser elaborada pelo protagonista.

\section{A confluência de mundos distantes e diferentes}

Partilhamos do mesmo espanto com relação a Menocchio: o moleiro é um sujeito cujo pertencimento social o alija imediatamente do mundo da cultura letrada (ainda que ele seja um caso isolado que conseguiu 'fraudar' as dificuldades de acesso a uma instrução formal e aos livros, na época), o que nos permite receber com surpresa a expressão de um pensamento que parece inapropriado ao sujeito pensante, quando consideramos as inúmeras impossibilidades com a quais alguém fora das classes cultas teria de lidar para adquirir livros e pensar com desenvoltura e livremente.

O modo de pensamento dominante na Idade Média era o catolicismo, de forma que nada acontecia no mundo laico que não fosse diretamente afetado pela idéia de Deus, o ponto mais alto e o fiador do sistema religioso, o que nos remete à concepção de uma época à qual um modo de produção, o feudalismo, e a Igreja, estão intimamente relacionados. Sabemos que o capitalismo só muito mais tarde viria a superar as formas rudimentares da economia feudal. Acreditamos que a intolerância às heresias, na época, não se reduz a um mero estratagema político para racionalizar a prática de perseguição e eliminação dos dissidentes. Ela provém da necessidade estrutural de manter a unidade ideológica indispensável para o funcionamento da própria base econômica. O capitalismo, ao contrário do regime feudal, funciona independentemente das idéias, concepções, religiões, atitudes, das ideologias, dos operários, capitalistas, técnicos, administradores ou consumidores que o fazem subsistir, embora não possamos eximir a influência que o regime de produção moderno exerce sobre a personalidade de Paulo Honório e justifique, até mesmo, muitas das brutalidades que ele 
comete contra os seus parceiros, os seus funcionários, as pessoas mais próximas (os amigos e Madalena).

Essas associações que sugerimos entre o feudalismo e o pensamento de Menocchio e entre o capitalismo e a escrita de Paulo Honório não querem apenas informar sobre as relações, conhecidas de todos, entre os modos de produção econômica e a repercussão destes no pensamento e na forma estética. Elas pretendem vislumbrar os 'condicionamentos' a que estão sujeitos os homens em suas relações com outros homens, como os comportamentos e os estilos de vida, o pensamento, as produções artísticas e as formas de comércio humano. Elas atentam também sobre as implicações existentes entre o modo de produção e o catolicismo e o pensamento desviante, para a época, de Menocchio, assim como o capitalismo e a 'ignorância' de Paulo Honório em conformação com o livro que pretende escrever. Não são meras especulações que procuram explicar a razão do comportamento ou do estilo de personagens tão diferentes que agregam algo de comum, que é o de pertencerem às camadas populares incultas, ao mesmo tempo em que se sobressaem dela, ainda que pobremente, pelo letramento. Não procuram apenas justificar o meio social como determinante do modo de ser de um indivíduo, mas querem sugerir sentidos que são produzidos por uma época, e se não pelas escolhas pessoais, ao menos encontrar uma 'justificação' do sujeito humano inserido num tempo e espaços específicos e movido pelas imposições dessas categorias.

Talvez reduzamos, com este tipo de abordagem aqui empreendida, a complexidade dos personagens Menocchio e Paulo Honório, e passemos ao largo de questões de suma importância, como é a da estrutura dos romances em que eles têm papel protagonizante. O que nos interessa, como amantes da literatura, é a ficção, a história, o modo como um Ginzburg e um Graciliano Ramos transformam homens tão medíocres e sofríveis em sua humanidade, como são o moleiro e o capitalista se vistos apenas como homens do mundo prosaico, e alçaos a essa categoria espetacular de seres preciosos e especiais, transcendendo como que, quase, a própria mesquinharia de que são frutos e que crivam suas ações, plasmando-os em sujeitos com os quais há tanta coisa que aprender, e aprender exatamente pelo que lhes falta em nobreza e dignidade.

Não partilhamos das 'teorias' que vêem com desprezo a fatura estética que se debruça sobre as questões que envolvem os meios populares ou que os representa, e têm sua fonte no melhor da tradição folclórica. Cremos que a forma do romance encontra sua realização plena por buscar desvelar a multifacetada riqueza 'escondida' nos espaços em que o bom-gostismo e o cânone teimaram em negá-la. Não fosse assim, não nos curvaríamos diante de uma personagem como Paulo Honório, não pela sua 'beleza' de caráter representada, mas 
admirados pelo modo como um criador, em posse de sua grande verve, pode provocar o esclarecimento humano através da grandeza da personalidade de um homem arruinado pelas próprias faltas, que o diminuem aos olhos de uma humanidade universal.

E ao invés de abominá-lo de nossa companhia, reclamamos sua presença, porque sabemos o quanto o que é posto no romance como falta de 'amoralismo' e decadência de valores nos impulsiona a ver criticamente a realidade circundante, e quanto o que lhe sobra em desumanidade nos ajuda a insistir mais na expressão do bem, como possibilidade de transcendência da barbárie.

Menocchio e Paulo Honório não ousam desmistificar a moral com suas ações. No entanto, eles avançam como sujeitos humanos e concebem, através das ilusões que a história e a cultura nos impuseram, que nos concentremos em alvos passíveis de serem partilhados e valores que devem ser defendidos a todo custo. Parafraseando Tchekhov, o homem se tornará melhor quando mostrarmos como ele é. E Menocchio e Paulo Honório são 'muito' eles mesmos! Através desses personagens não sugerimos uma função higienizadora à arte, nem tampouco uma forma especular de agir acertadamente, mas eles como que nos obrigam a não arredarmos da fé de que as formas estéticas, em 'pintar' o homem em toda a sua estatura, prometem alguma forma de redenção em meio ao desencanto do mundo das associações humanas.

\section{Referências}

BENJAMIN, Walter. O narrador: considerações sobre a obra de Nikolai Leskov. In: Magia e técnica, arte e política. São Paulo: Brasiliense, 1985.

GINZBURG, Carlo. O queijo e os vermes: o cotidiano e as idéias de um moleiro perseguido pela Inquisição. São Paulo: Companhia de Bolso, 2006.

LAFETÁ, João Luiz. O mundo à revelia. In: . A dimensão da noite e outros ensaios. São Paulo: Duas Cidades; Ed. 34, 2004.

LE GOFF, Jacques. História e memória. Campinas: Editora da Unicamp, 1996.

OLIVEIRA NETO, Godofredo. Posfácio. In: . RAMOS, Graciliano. São Bernardo. 83 ed. São Paulo: Record, 2006.

RAMOS, Graciliano. 83 ed. São Bernardo. Rio de Janeiro: Record, 2006.

SOUZA, Laura de Mello e. O diabo e a Terra de Santa Cruz. São Paulo: Cia. das Letras, 1995.

WEIRICH, Harald. Lete: arte e crítica do esquecimento. Rio de Janeiro: Civilização Brasileira: 2001. 